\begin{tabular}{|c|c|c|c|c|c|c|}
\hline \multirow{4}{*}{ Impact Factor: } & ISRA (India) & $=3.117$ & SIS (USA) & $=0.912$ & ICV (Poland) & $=6.630$ \\
\hline & ISI (Dubai, UAE & $=0.829$ & РИНЦ (Russia) & $=0.156$ & PIF (India) & $=1.940$ \\
\hline & GIF (Australia) & $=0.564$ & ESJI (KZ) & $=8.716$ & IBI (India) & $=4.260$ \\
\hline & JIF & $=1.500$ & SJIF (Morocco) & $=\mathbf{5 . 6 6 7}$ & OAJI (USA) & $=0.350$ \\
\hline
\end{tabular}

\section{SOI: 1.1/TAS DOI: 10.15863/TAS International Scientific Journal Theoretical \& Applied Science}

\author{
p-ISSN: 2308-4944 (print) e-ISSN: 2409-0085 (online) \\ Year: 2019 Issue: $05 \quad$ Volume: 73
}

Published: $30.05 .2019 \quad$ http://T-Science.org

SECTION 19. Management. Marketing. Public administration.
QR - Issue

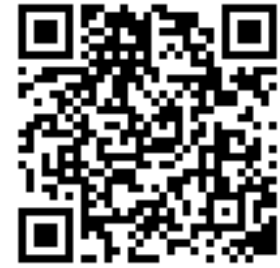

Svetlana Ivanovna Izaak $\mathrm{PhD}$, Deputy Head of the Department «Management in Sport» on science, Russian University of Transport (MIIT), Moscow, Russia e-sepp@yandex.ru

Vladislav Andreevich Kolovratov Master student of the Department «Management in Sport», Russian University of Transport (MIIT), Moscow, Russia

\title{
BRAND MANAGEMENT IN SPORT
}

Abstract: In article it is shown that in the markets with very high level of the competition the brand is the powerful tool for distinction and differentiation. It is noted that functioning of subjects of sport in the competitive environment updates development and implementation of the development strategy of the company including strategies of development for a brand as its component. An important problem of a brand management in the industry of sport is increase in efficiency of branding which can be reached by means of the following actions: applications of modern methods of strategic and tactical management of a brand; regular monitoring of a condition of own brand by the company and adoption of management decisions on the basis of availability of full and reliable information on target audience, the marketing environment, activity of competitors.

Key words: strategy, sports organization, brand, branding, brand management, naming.

Language: Russian

Citation: Izaak, S. I., \& Kolovratov, V. A. (2019). Brand management in sport. ISJ Theoretical \& Applied Science, 05 (73), 379-384.

Soi: http://s-o-i.org/1.1/TAS-05-73-56 Doi: crossef https://dx.doi.org/10.15863/TAS.2019.05.73.56

\section{БРЕНД-МЕНЕДЖМЕНТ В СПОРТЕ}

Аннотация: В статье показано, что на рынках с очень высоким уровнем конкуренции бренд является мощчным инструментом для различения и дифференциации. Отмечается, что функционирование субъектов спорта в конкурентной среде актуализирует разработку и реализацию стратегии развития компании, в том числе и стратегии развития бренда как её составной части. Важной задачей бренд-менеджмента в индустрии спорта является повышение эффективности брендинга, которая может быть достигнута посредством следуюших действий: применения современных методов стратегического и тактического управления брендом; регулярного мониторинга компанией состояния собственного бренда и принятия управленческих решений на основе наличия полной и достоверной информации о цчелевой аудитории, маркетинговой среде, деятельности конкурентов.

Ключевые слова: стратегия, спортивная организация, бренд, брендинг, бренд-менеджмент, нейминг.

\section{Introduction}

Национальный стратегический документ «Стратегия - 2030» определяет цели, направления, приоритеты развития страны, а также систему сбалансированных показателей достижения этих целей, глобальные тенденции, возможности и риски [13]. Реализация Национальной Стратегии и отраслевых Стратегий сопровождается разработкой и внедрением эффективных методов и технологий управления $[10,3]$. Выполнить намеченные стратегические индикаторы развития невозможно без квалифицированного персонала, профессионалов в данном вопросе, которые могут эффективно применять на практике инновационные технологии и инструменты менеджмента [2].

Одним из разновидностей менеджмента является брендинг (управление брендом). 


\begin{tabular}{|c|c|c|c|c|c|c|}
\hline \multirow{4}{*}{ Impact Factor: } & ISRA (India) & $=3.117$ & SIS (USA) & $=0.912$ & ICV (Poland) & $=6.630$ \\
\hline & ISI (Dubai, UAI & $=0.829$ & РИНЦ (Russia & $=0.156$ & PIF (India) & $=1.940$ \\
\hline & GIF (Australia) & $=0.564$ & ESJI (KZ) & $=8.716$ & IBI (India) & $=4.260$ \\
\hline & JIF & $=1.500$ & SJIF (Morocce & $=5.667$ & OAJI (USA) & $=0.350$ \\
\hline
\end{tabular}

Брендинг позволяет наделить компанию индивидуальными характеристиками за счет создания философии, целей, эмблем или фирменных цветов, что, несомненно, положительным образом влияет на деятельность организации, повышение её узнаваемости в рыночной среде [5].

Брендинг в России получил широкое распространение в последние годы, когда большинство компаний стали активно применять его возможности. Общеизвестно, что наличие в ассортименте портфеля «сильного бренда» в значительной степени способствует увеличению стоимости капитала, прибыли и объема продаж компании; закреплению рыночных позиций. Термин «Бренд» встречается в различных отраслях экономики, в том числе и индустрии спорта, что актуализирует изучение вопросов отраслевого бренд-менеджмента с позиции систематизации его основных теоретикометодологических положений.

Цель - изучить теоретико-методологические аспекты управления брендом в профессиональной спортивной среде.

\begin{tabular}{|c|c|c|}
\hline Methods of reseal & & \\
\hline Систематизация & основных & теоретико- \\
\hline методологических & & положений, \\
\hline регламентирующих & функциони & ование \\
\hline совершенствование бр & & нта в спорте, \\
\hline $\begin{array}{l}\text { осуществлялась Посре } \\
\text { широкого спектра лог }\end{array}$ & овом Приме & $\begin{array}{l}\text { ения в раооте } \\
\text { Іх методов, в }\end{array}$ \\
\hline $\begin{array}{l}\text { том числе системног } \\
\text { визуализашии научной }\end{array}$ & $\begin{array}{l}\text { анализа, а } \\
\text { дормаци }\end{array}$ & кже метода \\
\hline
\end{tabular}

Results and discussion

Сущность и содержание понятия «бренд». Бренд является определенной торговой маркой или товарным знаком. Для него характерна высокая степень известности и лояльности потребителя, которые позволяют воспринимать бренд как залог наибольшего соответствия свойств и качеств товара/услуги основным потребностям и предпочтениям потребителя. Понятие бренда включает в свой состав сам товар или услугу со всеми их характеристиками, набор ожиданий и ассоциаций, которые воспринимаются потребителем и предписываются товару, а также обещание ряда преимуществ, данных владельцем бренда.

К основным элементам бренда относятся:

- атрибуты (определенные характеристики и свойства товара/услуги, отражающие идею его основных преимуществ);

- выгоды (преимущества одного перед другим), которые разделяют на функциональные и эмоционально-экспрессивные виды;

- ценности (исключительные свойства товара/услуги, являющиеся отражением миссии предприятия-производителя или иной организации); в аспекте коммерциализации ценность бренда соответствует его финансовой стоимости.

Сущность бренда предполагает наличие нескольких уровней качества: функциональное качество или предназначение (способность бренда полностью удовлетворять запросы потребителя и свое функциональное предназначение); ценностные установки (отражаются в индивидуальности качества или ценности товара/услуги и определяются мировоззрением обычных покупателей); социальное качество (возможность покупателя ощутить свою принадлежность к более высокому социальному классу); коммуникативное качество (связь с потребителем и сохранение у него определенного интереса к своему бренду) [6].

Для поддержания бренда, также, как и продвижения товара/услуги на целевые рынки, применяются различные маркетинговые стратегии, разрабатываемые в зависимости от стадии жизненного цикла бренда. Одна из таких концепций предполагает разработку базовых стратегий с учетом четырех этапов жизненного цикла бренда [1]. В соответствии с этой концепцией жизненный цикл бренда соотнесен с жизненным циклом товара/услуги, который, в свою очередь, включает стадии, характеризующиеся выводом продуктов на рынок, ростом, зрелостью, упадком (рисунок 1).

В большинстве теорий представлено деление жизненного цикла бренда именно на четыре этапа, различающихся по целям маркетинговых мероприятий: в зависимости от ценовой политики ассоциированных с брендом товаров/услуг; целевой аудитории; продвижения и дистрибуции. Соответственно, названия этапов (роста и развития, зрелости, спада и т.д.) определяют суть жизненной стадии, на которой находится бренд.

Термин «бренд» с позиции теории маркетинга характеризует эмоциональное восприятие потребителем того или иного вида товара или услуги. Когда необходимо оценить бренд, то имеется в виду оценивание прав на торговую марку. Знание истинного положения дел о нём формируется в ходе осуществления организацией регулярного мониторинга состояния собственного бренда. Контрольные мероприятия, являющиеся частью указанных мониторинговых исследований, в том числе полученные на их основе данные, предоставляют возможности для оценки реальной ситуации. Результаты работы в данном направлении позволяют определить, на какой стадии развития бренда выгоднее всего применять те или иные стратегии его развития. 


\begin{tabular}{llllll} 
& ISRA (India) $=\mathbf{3 . 1 1 7}$ & SIS (USA) & $=\mathbf{0 . 9 1 2}$ & ICV (Poland) & $=\mathbf{6 . 6 3 0}$ \\
Impact Factor: & ISI (Dubai, UAE) $=\mathbf{0 . 8 2 9}$ & PUHL (Russia) $=\mathbf{0 . 1 5 6}$ & PIF (India) & $=\mathbf{1 . 9 4 0}$ \\
& GIF (Australia) $=\mathbf{0 . 5 6 4}$ & ESJI (KZ) $=\mathbf{8 . 7 1 6}$ & IBI (India) & $=\mathbf{4 . 2 6 0}$ \\
& JIF & $\mathbf{1 . 5 0 0}$ & SJIF (Morocco) $=\mathbf{5 . 6 6 7}$ & OAJI (USA) & $\mathbf{0 . 3 5 0}$ \\
\hline
\end{tabular}

\section{Цели}

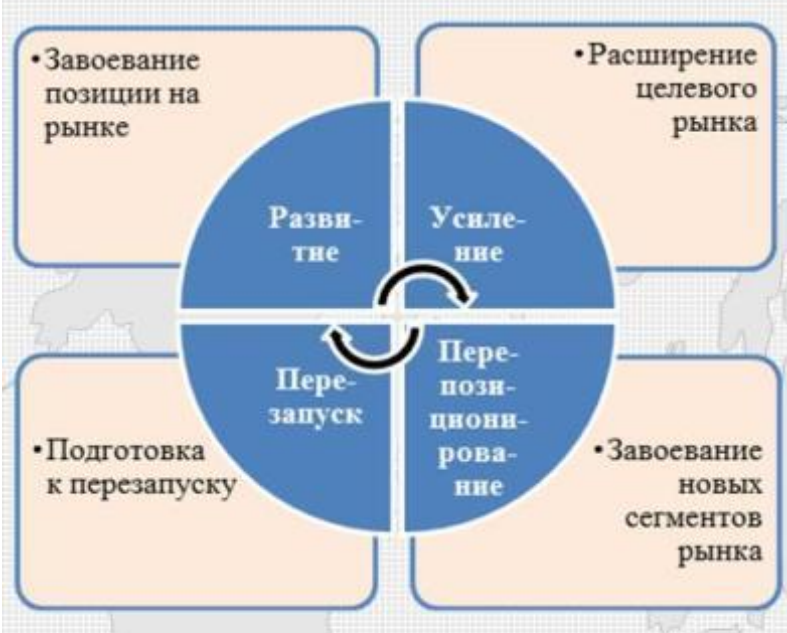

Продукт

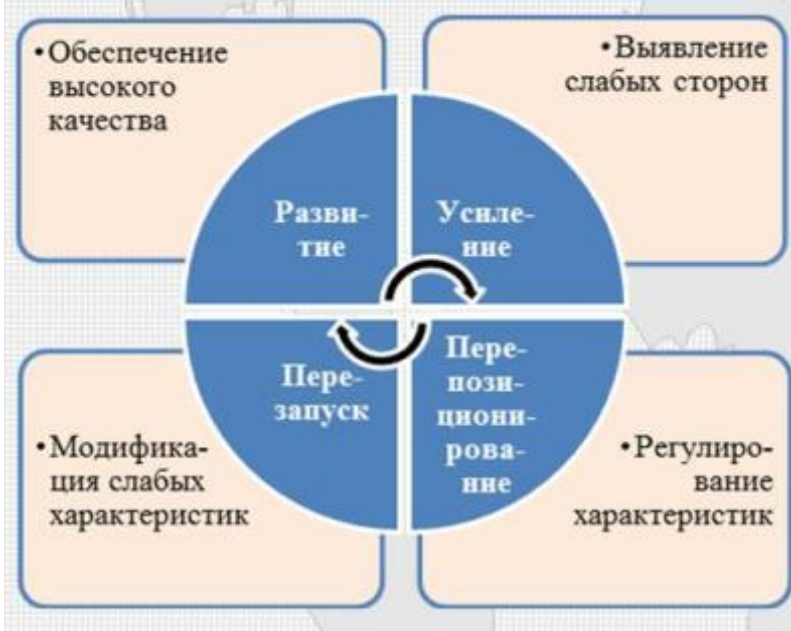

\section{Продвижение}

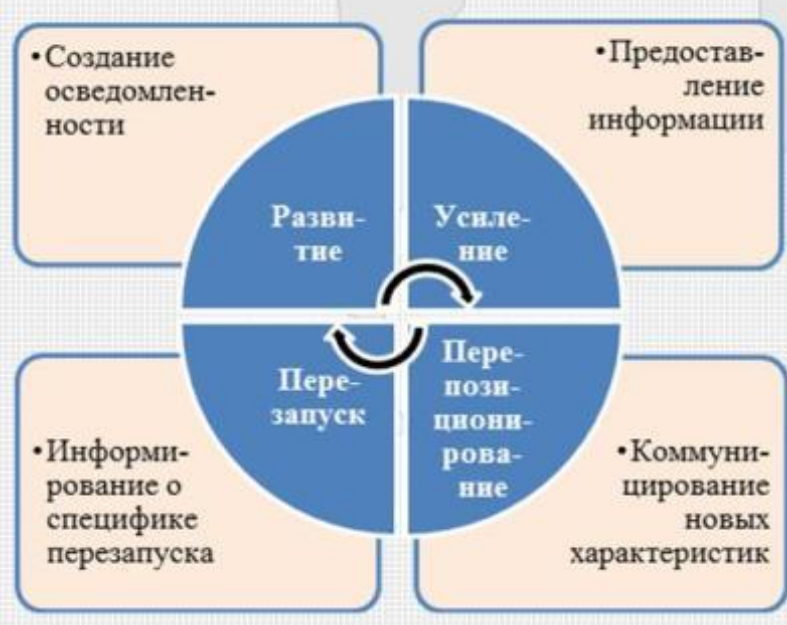

\section{Стадии жизненного цикла товара/}

услуги

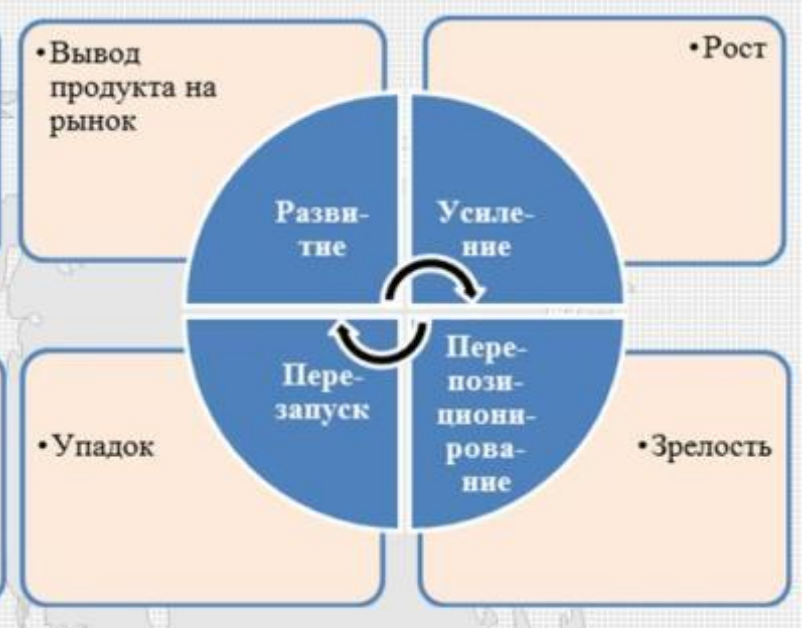

Цена

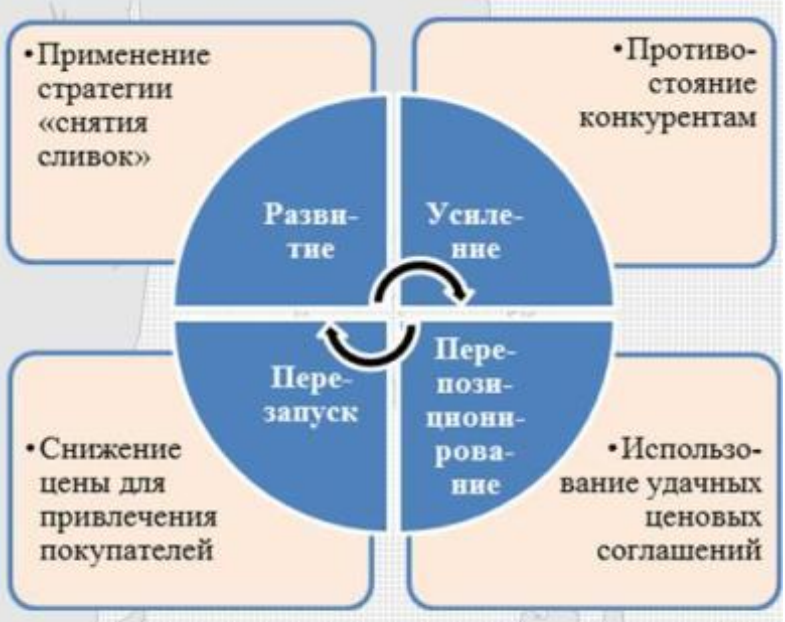

Дистрибуция

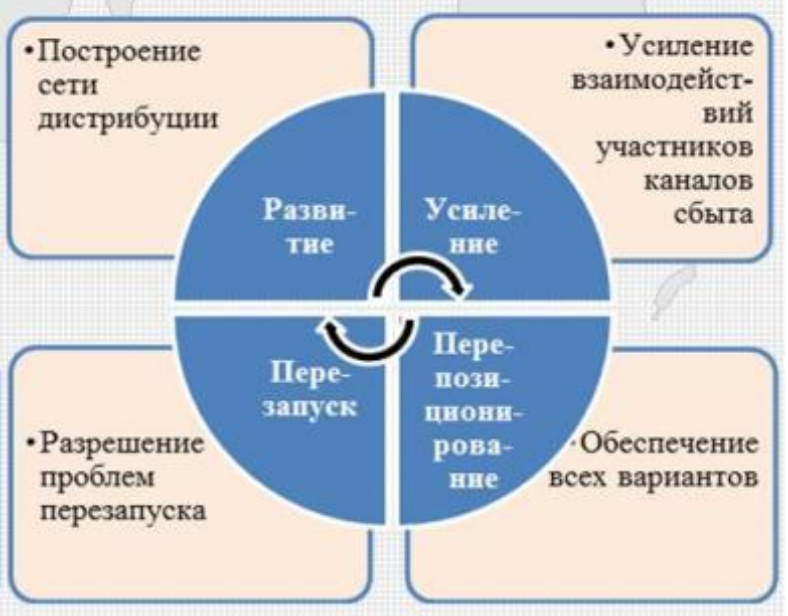

Рисунок 1. Жизненный цикл бренда. 


\begin{tabular}{|c|c|c|c|c|c|c|}
\hline \multirow{4}{*}{ Impact Factor: } & ISRA (India) & $=3.117$ & SIS (USA) & $=0.912$ & ICV (Poland) & $=6.630$ \\
\hline & ISI (Dubai, UAI & $=0.829$ & РИНЦ (Russia & $=0.156$ & PIF (India) & $=1.940$ \\
\hline & GIF (Australia) & $=0.564$ & ESJI (KZ) & $=8.716$ & IBI (India) & $=4.260$ \\
\hline & JIF & $=1.500$ & SJIF (Morocco & $=5.667$ & OAJI (USA) & $=0.350$ \\
\hline
\end{tabular}

Оценка текущего состояния бренда проводится с учетом информации о реальной ситуации на рынке товаров/услуг; результатов анализа конкурентов, покупателей, демографических данных и тенденций их изменения. Как правило, оценка текущего состояния бренда выполняется по четырем основаниям: потребности покупателя, среда маркетинга, конкуренты, стратегическое и тактическое бренд-планирование (формирование и корректировка индикаторов развития).

Управление брендом (брендинг). Управление брендом направлено на максимизацию марочных активов путем интегрирования средств и методов внутрифирменных механизмов на основе сбалансированного инвестиционного подхода к брендингу; осуществление сопряженных с ним коммуникаций как внутри компании, так и вне её. Существует огромное количество стратегий по управлению брендом $[11,12]$. Одними из основных и часто используемых являются стратегии расширения бренда, создания подбрендов и ко-брендинг.

Расширение бренда заключается в использовании известности и имиджа существующего бренда для запуска новых товаров или услуг. Реализация указанной стратегии направлена на решение новой задачи (в некоторых случаях комплекса задач), регламентирующей: выпуск товаров, дополняющих базовую модель или имеющих новое назначение; перенос имиджа бренда на смежную категорию товаров; замещение новой маркой существующий товар; привлечение новой целевой аудитории.

Преимущество данной стратегии состоит в минимизации финансовых затрат, так как используются общие каналы продвижения товара. Продвижение нового товара под старой маркой занимает меньше времени и сохраняет средства на его разработку. Если бренд знаменит и популярен, то между производителем и покупателем уже выстроены доверительные отношения. Потребитель подсознательно все преимущественные качества будет переносить на новую продукцию, предлагаемую производителем на рынке. Неблагоприятная тенденция, возникающая в процессе применения стратегии расширения бренда (её, несомненно, нужно отслеживать и корректировать), характеризуется «размыванием» бренда в сознании потребителя, низкой жизнеспособностью расширяющих брендов, а также тем, что затраты на развитие марки в долгосрочном плане выше у марочных расширений по сравнению с новыми брендами.

Подбренд или суббренд - это модифицированная марка, которая включает в себя большую разновидность товаров. Создается он для того, чтобы охватить еще один сегмент рынка; отличается от базовой модели простотой изделия, заниженным качеством и ценой. Другими словами - это бренд внутри бренда. Суббренд зачастую применяют в качестве способа борьбы с конкурентами.

Еще один популярный способ продвижения бренда - это ко-брендинг (взаимодействие брендов). Ключевая идея ко-брендинга заключается «в осознании корпорациями необходимости альянса для достижения конкурентных преимуществ и создании ему через совместный брендинг широкой известности у потребителей» [12].

Особенности бренд-менеджмента в профессиональном спорте. Спорт - сфера социально-культурной деятельности как совокупность видов спорта, сложившаяся в форме соревнований и специальной практики подготовки человека к ним [14]. Спорт содействует воспитанию, социальной сплоченности, укреплению здоровья, формированию образа и стиля жизни, предотвращению негативных явлений в молодежной среде [4, 7]. Спорт во всем своем многообразии видов, типов, методов, средств и форм организации направлен на развитие человеческого потенциала [8], построение миролюбивого общества. Рассматривая спортивную деятельность в международном аспекте, можно констатировать, что она способствует обеспечению национальных интересов и реализации стратегических национальных приоритетов; упрочению позиций России на международной арене как одного из влиятельных центров современного мира [9].

Популярность спорта на территории нашей страны повлияло на развитие бренд-менеджмента, особенно в профессиональной спортивной среде. В спортивных клубах работают бренд-менеджеры, которые создают привлекательный имидж команды для большего привлечения болельщиков, спонсоров, партнеров.

Бренд-менеджеры активно разрабатывают и продвигают бренд клуба в спортивной среде, который отличает его от других подобных организаций по ряду оснований: названию, дизайну фирменного стиля и логотипа, цветовому решению и иным элементам.

- Название клубов. Существует три основных типа нейминга команд, идентификатором бренда которых послужили названия городов, знаменитых мест; предприятий-спонсоров; местности и образный элемент. Общепринятое положение нейминга $\mathrm{c}$ учетом спортивной специфики состоит в следующем: чтобы название клуба стало популярным, оно должно быть легко произносимым, уникальным и созвучным, не быть 


\begin{tabular}{|c|c|c|c|c|c|c|}
\hline \multirow{4}{*}{ Impact Factor: } & ISRA (India) & $=3.117$ & SIS (USA) & $=0.912$ & ICV (Poland) & $=6.630$ \\
\hline & ISI (Dubai, UAE & $=0.829$ & РИНЦ (Russia & $=0.156$ & PIF (India) & $=1.940$ \\
\hline & GIF (Australia) & $=0.564$ & ESJI (KZ) & $=8.716$ & IBI (India) & $=4.260$ \\
\hline & JIF & $=1.500$ & SJIF (Morocce & $=5.667$ & OAJI (USA) & $=0.350$ \\
\hline
\end{tabular}

двусмысленным, а также привлекать внимание болельщиков.

- Цветовые решения. Сочетание цветов является важным элементом бренд-менеджмента. Палитра цветов выступает как индивидуальная характеристика клуба, позволяющая идентифицировать его, а также линейку клубных продуктов организации, предлагаемых на рынке.

- Торговые марки, эмблемы и вымпелы. Изображенные на эмблеме символы часто отражают идеологию клуба/команды (как и талисманы).

- Девизы и слоганы. Чаще всего фраза или группа слов, скомбинированные специальным образом, сжато выражают ключевой критерий ценностей спортивного клуба/команды.

Создание и продвижение бренда спортивного клуба актуализирует решение вопросов его правовой защищенности. Необходимо особо отметить, что бренд должен быть юридически «защищенным» для того, чтобы его использование/воспроизведение третьими лицами было запрещено в случае отсутствия разрешения спортивной организации, являющейся владельцем бренда. Для этого организация должна соответствующим образом взаимодействовать с уполномоченными по решению указанных вопросов ведомствами.

\section{Conclusion}

Систематизация основных теоретикометодологических регламентирующих совершенствование положений, функционирование и бренд-менеджмента в индустрии спорта, показала следующее.

1. На рынках с очень высоким уровнем конкуренции, характерным для зрелого рынка, бренд является мощным инструментом, применяемым с целью различения и дифференциации. Бренд - это знак, символ, имя, которое отличает товар/услугу одного производителя от товара/услуги другого производителя, а также создает ассоциативный ряд именно с определенной торговой маркой. Основа, которая заложена в понятие «бренд», - его маркетинговая сущность, ориентированная на то, что желает потребитель.

2. Для того чтобы быть «релевантным», бренд должен быть защищаемым (и защищенным), легким для произношения, быть узнаваемым и запоминаемым; он должен привлекать внимание, предполагать выгоды от продукта (функциональные, эмоциональные и т.п.) и, наконец, он должен позиционировать спортивную организацию или её предложение относительно конкурентов.

3. Непосредственно процесс управления брендом зависит от профессионализма маркетологов, которые проводят маркетинговые исследования, выявляют потребности и возможности приобретения клиентами товаров или услуг. В рыночных условиях, характеризующихся повышением конкурентоспособности

предприятий/организаций, востребованности их товаров/услуг на рынке, продвигать бренд также сложно, как и его создавать. Для реализации указанных целей можно использовать стратегии расширения бренда, создания подбрендов, кобрендинг. Каждая из этих стратегий имеет свои плюсы и минусы, поэтому при её выборе стоит учитывать особенности компании, в которой она будут применяться.

4. Функционирование субъектов спорта в конкурентной среде актуализирует разработку и реализацию стратегии развития компании, в том числе и стратегии развития бренда как её составной части. Важной задачей брендменеджмента в спорте является повышение эффективности управления брендом, которая может быть достигнута посредством следующих действий: осознания важности и ценности бренда руководством организации; применения современных методов стратегического и тактического управления брендом; регулярного мониторинга компанией состояния собственного бренда и принятия управленческих решений на основе наличия полной и достоверной информации о целевой аудитории, маркетинговой среде, деятельности основных конкурентов.

References:

1. Aaker, D. (2016). Aaker o brendinge. 20 principov dostizheniya uspekha. (p.256). Moscow: Eksmo.

2. Izaak, S. I. (2017). Tendencii razvitiya sportivnogo upravlencheskogo obrazovaniya $\mathrm{v}$
Rossijskoj Federacii // Sport: ekonomika, pravo, upravlenie, No. 3, pp. 27-30.

3. Izaak, S. I. (2018). Strategiya razvitiya sportivnoj otrasli: monografiya. (p.168). Moscow: Sport. 


\begin{tabular}{|c|c|c|c|c|c|c|}
\hline \multirow{4}{*}{ Impact Factor: } & ISRA (India) & $=3.117$ & SIS (USA) & $=0.912$ & ICV (Poland) & $=6.630$ \\
\hline & ISI (Dubai, UAE & $=0.829$ & РИНЦ (Russia & $=0.156$ & PIF (India) & $=1.940$ \\
\hline & GIF (Australia) & $=0.564$ & ESJI (KZ) & $=8.716$ & IBI (India) & $=4.260$ \\
\hline & JIF & $=1.500$ & SJIF (Morocce & $=5.667$ & OAJI (USA) & $=0.350$ \\
\hline
\end{tabular}

4. Izaak, S. I., \& Volodkovich, S. L. (2016). Aktual'nye problemy sohraneniya zdorov'ya studencheskoj molodezhi v Rossii i Belorussii // Chelovecheskij kapital, No. 5 (89). pp. 8-10.

5. Ischenko, M. M., \& Izaak, S. I. (2017) Innovacii. Predprinimatel'stvo. Sport. // Ekonomicheskie sistemy, T. 10. No. 3 (38). pp. 59-63. (DOI: 10.29030 / 2309-2076-2017-10-3-59-63)

6. Kapferer, Z.-N. (2007). Brend navsegda: sozdanie, razvitie, podderzhka cennosti brenda. (p.448). Moscow: Vershina.

7. Parshikova, N. V. (2016). Obrashchenie rukovoditelya Koordinacionnoj komissii Ministerstva sporta Rossijskoj Federacii po vvedeniyu i realizacii Vserossijskogo fizkul'turno-sportivnogo kompleksa «Gotov $\mathrm{k}$ trudu i oborone» (GTO) // Adaptivnaya fizicheskaya kul'tura, No. 1 (65), p. 2.

8. Parshikova, N. V., \& Izaak, S. I. (2016). Razrabotka strategicheskogo prognoza razvitiya fizicheskoj kul'tury i massovogo sporta na period do 2030 goda. Chelovecheskij kapital, No. 4 (88), pp. 10-12.
9. Parshikova, N. V., Izaak, S. I., \& Kovalenko, G. V. (2017). Sport v mezhdunarodnoj sisteme koordinat: novye vyzovy i vozmozhnosti. Teoriya i praktika fizicheskoj kul'tury, No. 7, pp. 94-96.

10. Parshikova, N. V., Izaak, S. I., \& Malits, V. N. (2017). Razvitie fizicheskoj kul'tury i sporta: strategiya budushchego. Teoriya $i$ praktika fizicheskoj kul'tury, No. 12, pp. 3-5.

11. Rep'ev, A. P. (2005), Mudryj reklamodatel'. (352). Moscow: Eksmo.

12. Rudaya, E. A. (2006). Osnovy brendmenedzhmenta: uchebnoe posobie dlya studentov vuzov. (p.254). Moscow: AspektPress.

13. (n.d.). Strategiya-2030: opredelenie celej $i$ prioritetov Retrieved Feb. 15, 2019, from http://open.gov.ru/events/5514805/

14. (2007). Federal'nyj zakon ot 04.12.2007 № 329$F Z$ (s izmeneniyami $i$ dopolneniyami) $« O$ fizicheskoj kul'ture $i$ sporte $v$ Rossijskoj Federacii» Retrieved Feb. 15, 2019, from https://base.garant.ru/12157560/ 